\title{
To Be or Not to Be Decolonized: A Medicine Wheel Healing Education Model
}

\author{
Theresa A. Papp \\ Department of Education Administration \\ University of Saskatchewan, Saskatoon, Saskatchewan, Canada
}

Received: April 10, 2018 Accepted: May 24, 2018 Published: May 24, 2018

doi:10.5296/jse.v8i2.13154 URL: https://doi.org/10.5296/jse.v8i2.13154

\begin{abstract}
Colonization has created a sea of troubles for Aboriginal learners through Eurocentric practices and principles that have marginalized learners resulting in lower educational attainment levels. The best reconciliation approach would be to decolonize classrooms so non-traditional learners who fail in mainstream classrooms can excel. This qualitative case study of a high school, mainly consisting of Aboriginal students, presents a medicine wheel healing education model that has decolonized and indigenized the classrooms resulting in improved educational outcomes, increased credit completion, attendance, and graduation rates. More important, students felt pride and improved self-esteem to be Aboriginal. The teaching style emulated traditional Aboriginal teaching by being hands-on, experiential, wholistic, personal, cooperative, flexible, and self-paced while incorporating Aboriginal culture and knowledge into the curriculum.
\end{abstract}

Keywords: Decolonization, reconciliation, teacher as healer, teacher traits, Aboriginal students, Aboriginal pedagogy, transformative leadership, medicine wheel healing education model, indigenized classroom, educational success 
To be, or not to be

To be, or not to be,

That is the question:

Whether 'tis nobler in the mind to suffer

the slings and arrows of outrageous fortune,

or to take arms against a sea of troubles,

and by opposing end them.

William Shakespeare [Hamlet]

The famous soliloquy -To be, or not to be-presents an abstract philosophical debate about struggles and questions the meaning of human existence. ReferencingAboriginal ${ }^{1}$ Peoples, to suffer the slings and arrows can be translated to the atrocities of assimilation, residential school abuses, racism, and oppression that Aboriginal peoples have encountered for centuries. For who would bear the whips and scorns of time, the oppressor's wrong, the proud man's contumely, strongly supports that Aboriginal people are determined To be, to maintain tradition and culture in quiet determination despite the relentless efforts of legislation and dominating authority of mainstream society; Not to bewas to not allow the annihilation of a race of Aboriginal peoples, languages, cultures and traditions.Aboriginal peoples have persisted, To be,and monumental events in Canadian history demonstrated this through the strong opposition to the White Paper of 1969, the Oka incident in Quebec in 1990 triggering the Royal Commission of Aboriginal Peoples (RCAP, 1996), and the most recent movement in 2012,Idle no More that sparked thousands of Aboriginal and non-Aboriginal people to come together to action.

Or to take arms against a sea of troubles, and by opposing end them?Colonization that attempted to ignore and destroy the Aboriginal culture has created the sea of troubles resulting in unsuccessful education ${ }^{2}$ experiences of Aboriginal students who continue to be marginalized by Eurocentric practices, principles, and pedagogy resulting in educational attainment levels that lag behind the non-Aboriginal people (Cherubini, 2014;Gordon \& White, 2014; Silver, 2013). Aboriginal peoples walk in two worlds: Their traditional world and the mainstream world. Past treaties affirmed the rights of Aboriginal peoples to education and medicine although the implementation of the treaties and the realization of these treaty rights remains a struggle (Battiste, 2013). The RCAP (1996) recommended numerous changes to the education system to include Aboriginal culture, language, and pedagogy. Education is viewed as the key ingredient to improving the conditions for Aboriginal peoples (Ponting, 1997).Decolonization is not the question but the answer; the question is when.

The purpose of this paper is to present a case study of a high school that had transformed the learning environments for Aboriginal students to reflect decolonized classrooms in which their students have experienced educational success ${ }^{3}$. These are hybrid classrooms that include Aboriginal pedagogy that is respectful of Aboriginal culture while meeting the requirements of mainstream education. What the teacher participants describe is a medicine wheel healing education model that nurtured their students to succeed and experience educational success for 
the first time in a mutually respectful environment. To best understand the transformed classrooms a discussion will first present Eurocentric mainstream pedagogical approaches juxtaposed to traditional Aboriginal ways of teaching and learning that include a literature review within each. Decolonization is discussed and explained within the Aboriginal medicine wheel philosophy and a healing education model. This review is enriched with observations of an educational institution with dominantly Aboriginal students taught by mainly Caucasian teachers. A further discussion is offered, based on primary research on how the school initially was transformed, the vision for change, teacher preparation and their professional development and the teacher attributes that represented the teacher as the healer. The teacher participants and administrators who were interviewed described how decolonization and healing was animated and how their classrooms adapted traditional Aboriginal academic approaches to teaching Aboriginal students. This paper expands the literature on the primary topics of decolonization, indigenization, and traditional Aboriginal pedagogy that goes beyond theory into classroom practice.

\section{Mainstream approaches to teaching and learning}

To begin, there exists the propensity for Eurocentric academia to define, compare and contrast, and compartmentalize, terminology to provide universality and a foundation for discussion (Haig-Brown, 1995; Hampton, 1995). Eurocentric categories are used as a point of reference continually determining what is right, wrong, acceptable or unacceptable. Academia carries biases developed from centuries of interpretations, categorizations and documentation. The comparison of worldviews co-exists in mainstream society with the belief that things and events exist independently. Haig-Brown (1995) cites Cajete (1986) who described western knowledge as "hierarchical, uniformistic, classification, quantitative and reflecting... only one direction in the relationship between cause and effect" (p. 265).Hampton (1995) affirmed the North American school is "a political, social, and cultural institution that embodies and transmits the values, knowledge, and behaviours of white culture . . . they assume that they possess the one true yardstick and that any [other] consideration . . .would simply lower standards"(p. 37).There exists an unquestionedacknowledgment that mainstream education is the best and most valid because it is recorded knowledge.

Morin (1998) described the dominant paradigm of education as one that follows society's industrial model with its primary objective to produce skilled workers through an education system that simulates the factory production lines wherein all learners gather at the precise location, at the times that replicate the general workforce, and all learners pass through the same process with the purpose to become socialized as good workers for the elite to maintain power and flourish.Consumers of mainstream education fall into this dominant paradigm.

Meeting the mainstream requirements dictates students must take specific subjects in school in prescribed disciplines of study with the required credits to graduate from high school. In the classroom, students must absorb and regurgitate the absolute correct answers. The levels of learning are graded by letter or number or through the use of terms such as meeting standards or developing. All decisions of subject matter to be learned, credentials for the educators, departmental examinations, grading, evaluation methods, learning outcomes, and requirements 
to attend postsecondary institutions are dictated by the governing departments. Teachers or faculty who have earned the deemed appropriate designations, such as a Bachelor of Education, deliver the course material often in a preach/teach format although different pedagogical approaches have been slowly seeping into the classroom. It is acknowledged that some classrooms offer alternatives such as cooperative, experiential, and play-based learning; however, reports have confirmed that transmission learning is the least effective method of classroom teaching but remains the most widely used (Scott, 2015; SSHRC, 2016).

Mainstream education is taught in silos and is fragmented into grade levels, disciplines and linear in design. Mainstream education is described as being linear, and follows a progression such as "A to B to C to D" (Little Bear, 2000, p. 82). Much like Figure 1, there is a beginning and an ending point rather than a circle in contrast to the Aboriginal view of lifelong learning. Little Bear (2000) further defined the linearity to manifest into hierarchical structure and power and education results in specialization into careers wherein some vocations are ranked with more prestige, such as a doctor compared to a mechanic, resulting in a social class structure. The linear perspective designates a person's value, and status is often dependent on the level of education, hence the higher the education, thehigher the status of the person.

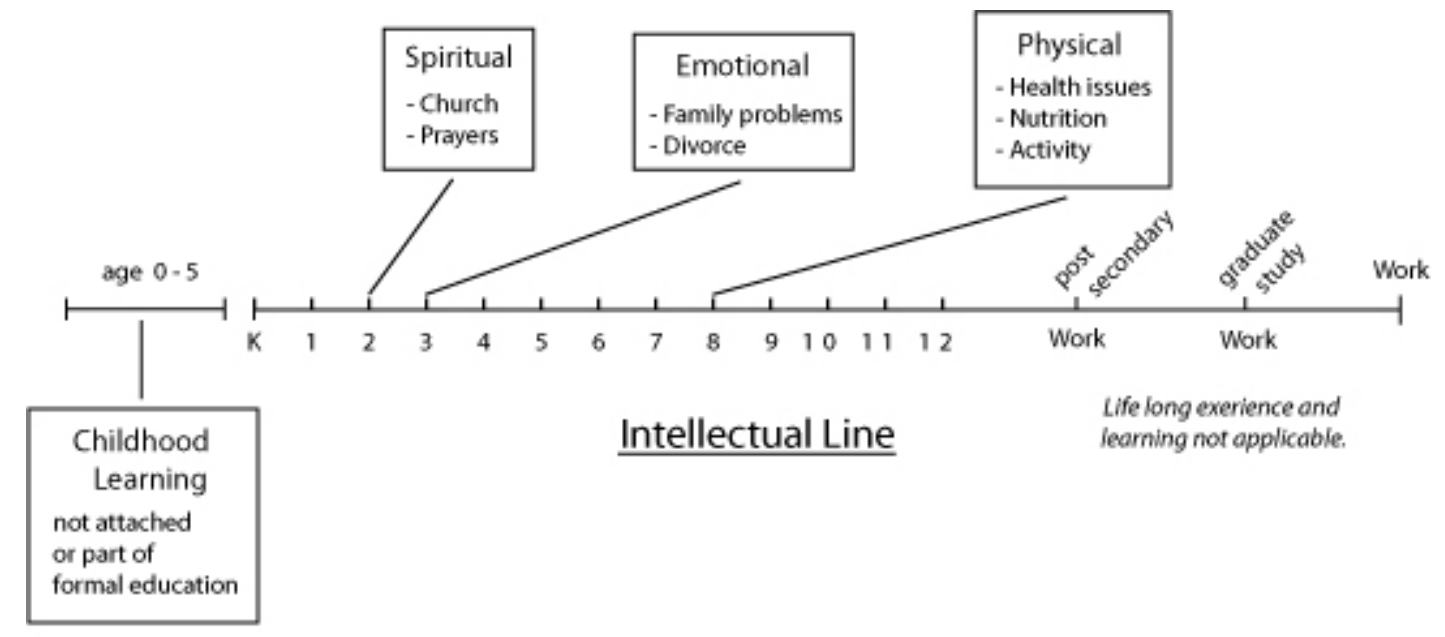

\section{Mainstream Education Model \\ Linear Depiction}
Primary component is the intellect. Fragmented into grades that must
be sequentially reached according to the measures set by the education system.

Figure 1. Mainstream Educational Model: A linear perspective

The mainstream approach to education and learning is described as "secular, fragmented, neutral/objective, and seen to discover definitive truth" (Curwen Doige, 2003, p. 147). Of the four components of the medicine wheel, the intellectual or knowledge is the primary concern of mainstream education focusing on the institutions of learning. Curwen Doige further stated that "the Western secular system of education appears to be blind to the spirituality that infuses and underlies Aboriginal epistemology" (p. 144) and clarified that spirituality is not about 
religious practices in the school. The notion is explained that "spirituality and learning in education refers to the connections between the intellectual and moral qualities of a student that must not be neglected, but rather accepted, respected, and celebrated by teachers" (p. 148). Aboriginal students conceptualize differently than non-Aboriginal students (Cajete, 1994; Curwen Doige, 2003; Hogue, 2016; Kanu, 2011; Pewewardy, 2002; Pewewardy \& Hammer, 2003). Pewewardy (2002) stated, "often teachers view differences in approach to learning as problems inherent in the students themselves, rather than as a lack of understanding by the teacher" (p. 34). The next section with provide an explanation of traditional Aboriginal ways of teaching and learning.

\section{Traditional/Aboriginal ways of teaching and learning}

The traditional Aboriginal way of teaching and learning does not exist in its purest form in today's classroom as it did generations ago. Traditional knowledge was handed down from generation to generation and varied between clans (Battiste \&Henderson, 2000; Castellano, 2000). The traditional teachings pass along the origin of the world and clan, boundaries, treaties, genealogies, ancestral rights, ancestors, animal spirits, and cautionary tales to reinforce values and beliefs (Cajete, 1994; Castellano, 2000). Aboriginal teaching and learning was considered a lifelong endeavor and said to be personal, oral, hands-on, experiential, wholistic, and conveyed in narrative or metaphorical language (Archibald, 2008; Cajete, 1994; Castellano, 2000, 2016; Couture, 2011). Empirical knowledge was gained over time and through observation demonstrating specificity to ecosystems experienced by a particular tribe. Also, what was traditionally deemed necessary to learn is different from the topics dictated as essential by mainstream society.

The intent of traditional Aboriginal teaching and learning is a wholistic approach intended to develop all aspects of the individual. Traditional Aboriginal teaching involved the four quadrants of the person: spiritual, emotional, physical, and intellectual (Archibald, 2008; Cajete, 1994, Castellano, 2000, 2016; Couture, 2011; Simpson, 1998). The traditional Aboriginal approach to teaching and learning demonstrates the interrelationship between all aspects of the learner, all other people, and nature with the desire to find balance and harmony (Castellano, 2000). Elders are highly valued within the Aboriginal community and are bestowed the responsibility of teaching the young. Mentors or aunties and uncles provide the support to the learner, demonstrating Aboriginal learning and teaching is a community responsibility (Gruber \& Coldevin, 1994; Lambert, 2004). Evaluation was determined by displayed competence and daily life.

\section{The Medicine Wheel: A symbol of Wholeness}

It should be noted that the concept of the medicine wheel is not universally accepted among all Indigenous peoples and scholars. The choice of words - Medicine and Wheel come with both negative and positive associations. For some, the need to use medicine congers the notion that Aboriginal peoples are sick (W. Ermine, personal communication, February 2005) or the White Man bringing the wheel to this country along with other Eurocentric means to assimilate the Aboriginal people (S. Wilson, personal communication, January 2005). For others, the wheel or circle symbolizes all things are interrelated, and the personal determination is to achieve 
balance and harmony.

This paper adopts the symbol of the Sacred Circle to represent the cyclical interrelationship of the emotional, spiritual, physical, and intellectual components of the medicine wheel. Couture (2011) explained the symbolic circle was centered and quartered to signify wholeness, inclusiveness, that is balanced and in harmony with all nature. All quadrants of the human must be equally honoured as they are interrelated and must be equally developed (Castellano, 2016; Graveline, 1998).

The medicine wheel is divided into four quadrants. These four quadrants have been used in a variety of ways to represent interconnectedness between a variety of terms associated with the person and nature. Some examples are provided by Graveline (1998) and are shown in Table 1.For this discussion, physical, intellectual, spiritual and emotional will be used.

Table 1. Medicine wheel comparisons (Graveline,1998)

\begin{tabular}{|l|l|l|l|l|l|}
\hline Option 1 & Option 2 & Option 3 & Option 4 & Option 5 & Option 6 \\
\hline North & Physical & Winter & Night & Elder & Earth \\
\hline East & Intellectual & Spring & Dawn & Child & Air \\
\hline South & Spiritual & Summer & Noon & Youth & Fire \\
\hline West & Emotional & Fall & Dusk & Adult & Water \\
\hline
\end{tabular}

The Aboriginal approach to education seeks to find a balance between all four components of the physical, intellectual, spiritual and emotional of the student whereas mainstream education places "an emphasis on intellectual cognitive achievement at the expense of spiritual, social and physical development” (RCAP, 1996). RCAP (1996) reported:

In the Aboriginal educational tradition, the individual is viewed as a whole person with intellectual, spiritual, emotional and physical dimensions. Each of these aspects must be addressed in the learning process. Holistic education is the term used to describe the kind of education traditionally used by Aboriginal peoples. Such education is organized to develop all aspects of the individual (Vol. 3, p. 415).

Knowledge needs to be presented and learned in an experiential or hands-on approach and comes from the perspective that addresses all four quadrants of the person.

\section{Aboriginal Knowledge and Teaching: The Challenge}

Based on the previous sections juxtaposing Aboriginal pedagogy to mainstream education, and the current educational requirements set by mainstream expectations, there emerges a contradiction in the attempt to create and distribute curriculum that meets the needs of the Aboriginal learner while at the same time meets the institutional requirements of established standards set by mainstream society. Scholars have acknowledged the paramount importance to include the facets of Aboriginal knowledge, culture, and the history of colonization to expand the parameters of the current education system (Battiste, 2013; Castellano, 2016; Little Bear, 2009). The decolonization process would consider Aboriginal values and how the content should be learned based on a new direction related to "theories firmly based on the 
traditions of our [Aboriginal] people" (Kirkness, 1998, p. 11).

Castellano (2000) explained Aboriginal knowledge is a recognized teaching and learning philosophy and stated, "Aboriginal knowledge is said to be personal, oral, experiential, holistic, and conveyed in narrative or metaphorical language" (p. 25). This wholistic view recognizes that there are a variety of knowledge sources: Traditional knowledge, empirical knowledge, and revealed knowledge all of which is grounded in the self, the spirit and the unknown (Castellano, 2000; Ermine, 1995). Castellano (2000) indicated, "Aboriginal knowledge is rooted in personal experience and lays no claim to universality" (p. 25).

Scholars have attested that introducing Aboriginal knowledge and Aboriginal pedagogy into the classroom affirms Aboriginal culture and builds attachment, self-esteem, and makes the curricula more meaningful for the Aboriginal students (Papp, 2016; Curwen Doige, 2003; Hammond, 2015; Kanu, 2006; Leddy \& Turner, 2016). Validating Aboriginal epistemology by "moving it out of the margins" and into the center of curriculum and education would benefit not only Aboriginal students but benefit all students (Leddy \& Turner, 2016, p. 53).

Aboriginal students benefit from culturally-responsive schooling, and that strategy has resulted in increased academic achievement levels and improved self-confidence (Papp, 2016; Castagno \& Brayboy, 2008; Hammond, 2015; Kanu, 2011; Pewewardy \& Hammer, 2003). Culturally responsive teaching practices is described as "sensitive, aware, and capable of employing cultural learning patterns, perspectives, family structure, multiple worldviews, and tribal languages in the teaching, learning, and mental ecology of the classroom" (Pewewardy, 1998, p. 31).

The lack of Aboriginal culture and language in the classroom has eroded the Aboriginal students' sense of self-worth and lowered their self-esteem (Kanu, 2006, 2011), and deemed a crucial factor of why Aboriginal students do not succeed in school (Bell, Anderson, Fortin, Ottmann, Rose, Simard, \& Spencer, 2004; Kanu, 2006, 2011).Silver, Mallett, Greene, and Simard (2002) recorded that Aboriginal high school students wanted to have more Aboriginal content in the curriculum and to know more about their culture and history. Allowing Aboriginal students to understand the historical context of colonization explains the educational lack of success was not a personal failing, but the collateral damage colonization has had on Aboriginal peoples.

What follows is a reporting of one case study and classroom observations that have incorporated traditional Aboriginal teaching styles and authentic culture into mainstream classrooms and the educational successes achieved.

\section{Research Methodology}

This is a qualitative case study of a high school in urban Saskatchewan, Canada with mostly Aboriginal students. The case study was to gain an understanding of the strategies that teachers implemented in the classroom that engaged students and resulted in students attending school and persevering to obtain credits to graduate. The observations in the classroomswere to determine how the teachers animated the strategies and techniques. The research represented an interpretive or constructivist approach that focused on the perceptions and beliefs of the 
participants as well as the researcher's interpretation of their perspectives (McMillan \& Schumacher, 2010)triangulated with the observations to deepen the researcher's understanding. An Appreciative Inquiry (AI) framework guided the research and was chosen because the school and the teachers were taking affirmative action in a positive approach that affected the Aboriginal students to achieve academic success (Ludema, Cooperrider \& Barrett, 2001). The research used grounded theory (GT) to guide the data collection and analysis to provide comparisons and conceptualizations (Charmaz, 2011; Glaser, 2002; Glaser \& Strauss, 1967).

The methodology was congruent with the Aboriginal philosophy of giving back to the community and respected the participants (Acoose, Blunderfield, Dell, \& Desjarlais, 2009; Kovach, 2009, 2010; Wilson, 2001).In vivo coding was used which Saldana (2013) explained uses verbatim codes to honour the participants by using their words and is consistent with an Indigenous method. An Aboriginal division administrator was contacted and the research proposal discussed and endorsed. Upon research ethics approval and completion of data collection, both the researcher and the administrator reviewed the findings.

\section{Site Selection and Participant Selection}

This school was selected because of the demonstrated evidenced-based outcomes of credit completion, attendance and graduation rates over a four-year period. The participants were purposefully selected and consisted of seven people. There were four teachers, two teacher/administrsators, and one division administrator. Three were self-identified as Aboriginal, two were female and five were male participants. The participants taught together for four to six years.

\section{The Findings: A Decolonized Classroom}

At the time the research was conducted, the school hosted approximately 300 students in grades 9 to 12 from 51 First Nations across Saskatchewan of which 56\% were living independently, and 20\% had children of their own. Between 2010 and 2014, the credit completion improved from $31 \%$ to $81 \%$, attendance increased from $52 \%$ to $77 \%$ and graduation rates increased from 3 to 55 (personal communication, CG, November 17, 2016). This section begins with the initial transformation of the school through a transformative leadership direction. This is followed by the professional development that was instrumental in providing the skills necessary to both transform the classroom and to prepare for the role of a healer/teacher.

\section{Transformative Leadership: A Vision for Change}

The school had previously experienced success in cultural healing and drew students to the school; however, the school leadership also wanted the school to experience academic achievement,and the school was mandated for renewal (personal communication $\mathrm{CG}$, November 17, 2016). The division administrator reviewed the statistics on attendance, enrolment, attrition, and credit completion and became the change agent with a vision for change. The Parent-Counciland community representatives, who represented advocacy for the students, also offered support. 
The iterative process of the turn-around was strategically planned and required an organizational change in numerous stages. The methodicalmodifications began by upsetting the complacency and asking critical questions that addressed the poor statistics and then acted on the answers by eliminating the deficit-thinking attitude. This resulted in some staff leaving and bringing in new staff and transforming the school.

The next strategy was to introduce innovation and Greg explained, "When you brought in a new team it was helping them see the possibilities, resourcing their innovation, no idea was a bad idea . . . trying to build enthusiasm for being there". The staff was encouraged to try new teaching strategies and provided funding. The school was viewed as an inventive incubation site for ideas and innovations.

Another component was to offer confidence and support to the administrative leadership. Greg stated this was a move from "the disruptive innovation and upsetting complacency into more of a sustainable leadership." Sustainability was supported by the division to engineer autonomy while the school administrators were in the classrooms every day supporting teachers and collaborating to develop a change in teachers' practice - one teacher at a time.

\section{Teacher Preparation: Professional Development and Administration Support}

One of the most significant differences noted by the teacher participants was the emancipatory style of leadership of the administrative staff; it was a shared leadership. Faye stated, "When I got here, compared to what it was in other places, where I felt like I was rather working for somebody not necessarily with somebody". The administration was described as the finest with the ability to delegate responsibilities, be supportive and nurturing, and allowing teachers to explore new ideas to help the students succeed based on trust of the teachers' capabilities. One of the primary supports appreciated by the participants was they felt respected as professionals and offered carte blanche. There was not a hierarchical experience between administration and staff.

All teachers would have professional development (PD) staff meetings on pedagogy, led by the school administrators, once a week for one hour for four years creating a feeling of comradery. The meetings were about pedagogy. The themes covered different resources, student engagement, inquiry-based learning, and problem-based learning. Adam felt the sessions were beneficial and "we would actually talk about the kind of things that would happen in the classroom and that would give collegiality and familiarity among the staff, support from one another, and a sharing of ideas. That is a huge support". In some cases, the PD was a book study; the staff would all read the same book and meet regularly to discuss the possible application at the school.

The administrators also spent time in the classrooms with the teachers, which provided an opportunity to get to know the students and the teachers. Teachers collaborated with the administrative staff in developing projects, co-planning, and co-teaching as an opportunity to co-construct PD. The focus of the school was to animate interactive pedagogy. It became a directive that every teacher in the schoolprepare one unit that was project-based. 


\section{Teacher Attributes: Teacher as Healer}

The interview process revealed specific personality traits that the teachers had in common. This is of importance to administrators when hiring teachers that will be teaching Aboriginal students. The Cree word okiskinohamakew is a teacher who serves as a guide (Katz \& St. Denis, 1991). Teachers as healers are people who serve and put into practice learning through dialogue, respect, and teaching by example giving students time and space to learn and develop in their own way. Mostly, the teacher as healer is described as "teaching comes from the heart; loving and caring for her students, the teacher generates love and care in her students, and mutual respect emerges" (Katz \& St. Denis, 1991, p. 30). This form of teaching is derived from traditional Aboriginal Cree as a wholistic approach that connects the person with culture and community (Katz \& St. Denis, 1991).

Battiste and Henderson (2000) believed that educators of Aboriginal students must walk in both worlds; the world of Aboriginal knowledge and the mainstream society and that educators are the keys to transforming education to benefit the Aboriginal learner. Battiste and Henderson (2000) stated:

Indigenous educators need to transform this way of knowing. They need to balance traditional Indigenous ways of knowing with the Eurocentric tradition. They must respect and understand the other ways of knowing. They must embrace the paradox of subjective and objective ways of knowing . . but bring us all into a living dialogical relationship with the world that our knowledge gives us (p. 94).

Educators must also live with the contradictions that exist between the expectations of meeting the requirements set forth by educational policy and meeting the needs of the Aboriginal learners.

One of the first questions asked of the participants was what influenced the participants to decide to teach at this school? In all cases, the participants saw coming to teach at this school as a challenge and an opportunity. In some instances, teachers had previously taught together and had an established rapport. For other teachers, they saw this as an opportunity to try new teaching approaches. The school had been known to be flexible and open-minded in teaching approaches, and this appealed to these teachers. Faye recognized that the way she was delivering content was not as effective as it could be for her Aboriginal students and welcomed the opportunity to be part of revitalizing and revamping the school to help students learn. She aspired to improve her teaching ability so that students would succeed.

Further, in that vein, the teachers were open-minded and willing to try new teaching approaches. In many ways, by changing teaching strategies, these teachers were risk takers who were allowed to explore different teaching methods to help their students be more successful in learning course content. Faye attended a workshop on problem-based learning and felt that it was a perfect fit for the school and her classroom. The teachers aspired to improve their ability to teach so their students would succeed. Two of the teachers were taking their master's degree in education to further expand their knowledge. The curriculum was taught in an experiential nature utilizing an inquiry-based approach. 
The attitudes of the teachers are essential. The teachers who were interviewed were passionate about the subjects they were teaching as well as how they were teaching their students. Through their excitement for learning, they felt they inspired their students. Adam expressed the notion that if the teacher loves what he or she is teaching that should inspire the student and stated, "They may not love it, but they might at least be interested because you are so gung-ho about it". In delivering the curriculum the teachers relinquished their power in the classroom and allowed students to be in the directive role in that students chose topics of interest and directed their own learning. There was a shared democratic leadership that demonstrated mutual respect and equality. There was no hierarchy present and everyone was on a first-name basis.

The teachers could be described as emotionally present and demonstrated genuine care for their students. Relationship building was an important trait. They were interested in their students and invested in their students' success. The teachers were aware of the challenges their students were encountering and acknowledged students for who they were in an accepting manner. They demonstrated respect and equality with their students and were personable by engaging in real conversations on a person-to-person basis and not the teacher-to-student conversation. A family-like relationship was developed that was explained to be the basis of teachers not requiring any classroom management of misbehavior or disrespect.

The dominant common thread that came from the participants was their openness to Aboriginal culture and Aboriginal people and willingness to experience the culture every day in a genuine manner. The teacher trait of willingness to accept the Aboriginal perspective contributed to the relationship building with the Aboriginal students. It should be noted that only two of the teachers interviewed were Aboriginal. When asked about special preparation to teach Aboriginal students, Faye noted, “I don't think there was any sort of preparation other than just being open to trying new things and I think often times we get hung up on practices that work for Aboriginal students when in reality they [practices] work for every student." It would also be noted that the celebration of culture was genuine and not a token gesture. The students appreciated the teachers' participation in the Aboriginal culture and this was interpreted as respectful. Above all, the teacher participants demonstrated teaching styles that exuded genuine warmth and caring to their students. The teachers attended to all four quadrants of the Aboriginal student with care and understanding. The following section describes how the teachers addressed the four domains in their classrooms.

\section{Incorporating Aboriginal Knowledge and Teaching into Mainstream Classrooms}

Drawing from the findings, this section presents a Aboriginal medicine wheel healing education model (see Figure 2) and the explanation of the approach taken by the teachers to improve the learning environment. The healing model of teaching is explained as it relates to the Aboriginal learner and the interrelationships of Aboriginal learning as it begins with the self and connects to the larger community ending with the self.

The teachers of these Aboriginal learners had adopted a traditional Aboriginal focus and instilled culture into their teaching style. The classrooms were infused with Aboriginal culture, 
ceremony, and language in the schools. Aboriginal concepts were also dispersed into the curriculum, with the direction of Elders, and content was directed collaboratively with the students. A wholistic approach to teaching the students attended to their spiritual, emotional, physical and intellectual needs.

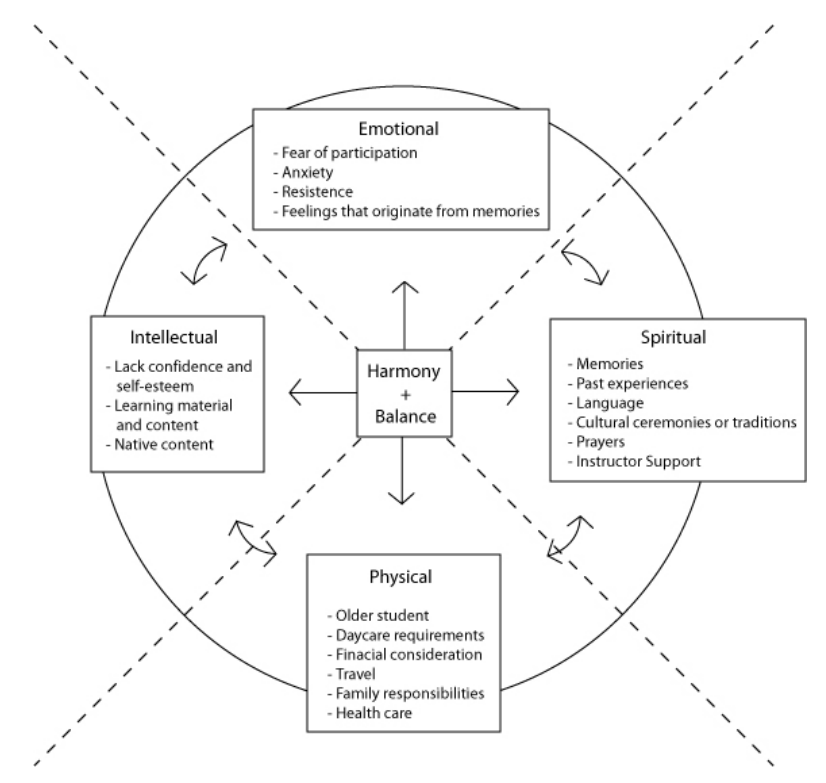

Figure 2. An Aboriginal Medicine Wheel Healing Education Model

The writer resists compartmentalizing the medicine wheel into four distinct quadrants but feels that Figure 2 displays the permeability of all components with each other, the cycles of life and nature. At the forefront, before subject matter, is the understanding of the realities the Aboriginal learners bring with them to the learning experience. These realities revolve around the emotional fears, anxiety, and resistance to learning based on negative past experiences that have often damaged the spirit of the student and teachers must be aware of "the internalized pain that students bring to the classroom" from their past experiences (Silver, 2013 , p. 7). The result of colonization has led to a sense of shame and education must "replace what is too often a sense of shame about being Aboriginal, with a sense of pride in being Aboriginal" (p. 8). These adverse experiences in the classroom are often augmented by teachers using humiliation and shame that also damages the spirit (Cleary \& Peacock, 1998; Pewewardy, 2002). Adult Aboriginal researchers recalled "I was often ridiculed and was called hurtful names on a regular basis" (Michell, Chief, Diubaldo, Klyne, McNab \& Smith, 2013, p. 17). MacKinnon (2013) suggested that teaching should be about "healing the spirit first is the key to success" (p. 57) for Aboriginal students. Teaching that begins with a healing process is demonstrated in Figure 2.

The spiritual domain can refer to feelings a learner has towards his or her culture and past experiences in the classroom and the connection made between intellect and morals while respecting and accepting the student (Curwen Doige, 2003). The instructor, by being 
supportive and displaying genuine concern, respect, and equality for the student fosters a healing that reconnects the student to the learning process through the teacher-student relationship. The emotional section will be closely connected to the spiritual as the learners may demonstrate fear, anxiety, and resistance because of their feelings from memories. The intellect will relate to the spiritual and emotions demonstrated by the learner and may show a lack of self-confidence and uncertainty as the learner relates to the learning material again based on past experiences. Hammond (2015) explained how the student must feel safe and accepted before learning can take place. Finally, the physical needs of the learner are interrelated to the other three components regarding needs for encouragement, flexibility, and accommodation to family or personal requirements. In classroom learning, the teacher participants confirmed that Aboriginal students benefit from instructor support allowing the student to gain confidence privately before sharing with the class and to gain trust with their teachers.

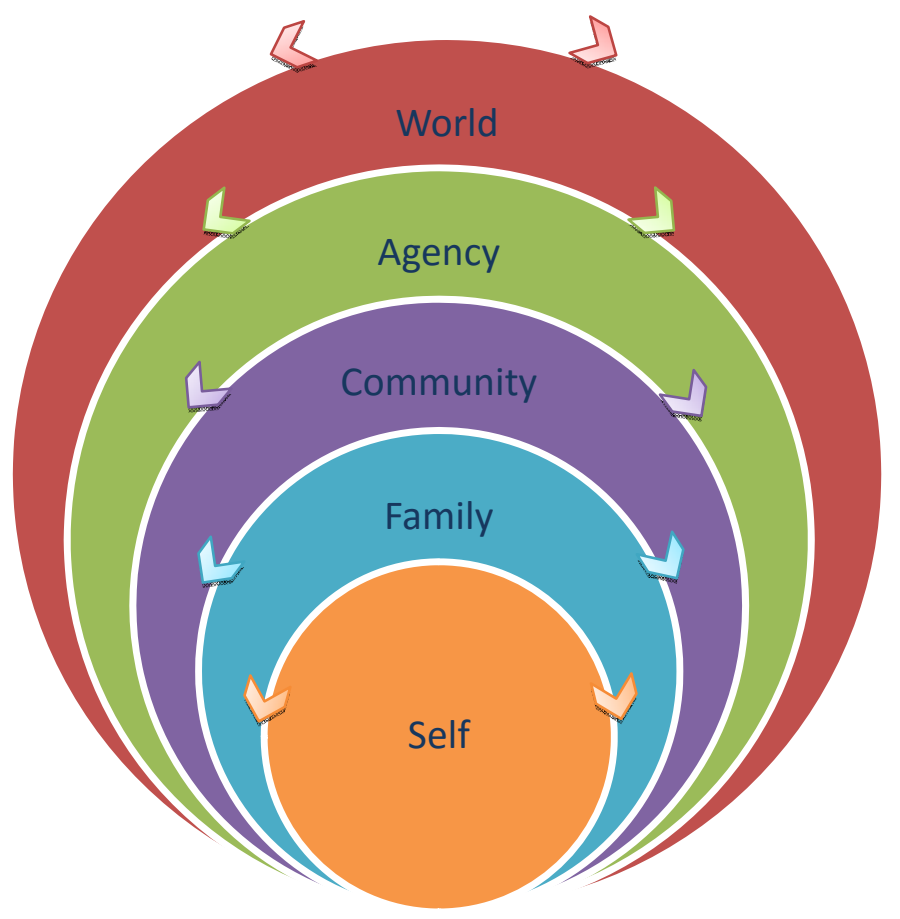

Figure 3. The spiral of interrelationships is beginning with the self and ending with the self

Figure 3 represents the interrelationship of the self with the community and larger world. This concept spirals within the medicine wheel offered in Figure 2. Together they represent the constant state of flux the self is in with the broader community. Arrows spiral in both directions emulating from the person and returning to the person, expressing the interrelationships of the person with the world. The remainder of this section will explain what was occurring at the school and the interaction of the teacher and student within the Aboriginal medicine wheel healing education model.

\section{Spiritual}

Spirituality is paramount and exemplified by the cultural ceremonies and traditions celebrated in the classrooms such as smudging and talking circles. Circle time was deemed significant for 
students and teachers to share their struggles and teachers demonstrated humanness. Many students did not know the teachings or protocol around the various ceremoniesand the Elders offered advice to both students and teachers. The classrooms had Aboriginal artifacts such as dream catchers and Native artwork. The culture was also part of the curriculum. Students are offered classes to learn their Native languages in Cree as well as Native Studies.

Teachers commented that including Aboriginal language, knowledge, and the culture and celebrations brought pride to the students. At graduation time, videos were prepared with the graduating students and repeatedly the common theme talked about students was how much pride was developed at the school to be Aboriginal and learn and experience their culture. Incorporating Aboriginal culture into the curriculum demonstrated the intellectual intermingling between the spiritual and emotional, placing value on the Aboriginal heritage. The opportunity to learn their language and heritage at the urban school rebuilt their spirit that was possibly defeated through lack of success in mainstream education.

\section{Intellectual}

Assessments were modified beyond paper and pencil tests offering the students a variety of evaluation styles, mainly formative assessments, to demonstrate their learning. Competency in learning the curriculum was not compromised or modified. For example, mathematics courses met provincial standards and the students completed and passed the departmental exams. The students and teacher would prepare and study as a group in pizza sessions.

The school maintained the requirements mandated by the Department of Education; however, the students were allowed flexibility to complete assignments and pacing was allowed to reflect the community activities, social, or family issues that would interfere with classroom attendance. The teachers offered this approach and found it well accepted. Research suggested a suitable program for Aboriginal learners will provide manageable workloads offering flexibility to allow the Aboriginal learner to attend to life and family responsibilities (Spronk, 1995; Voyageur, 2001). The school offered a credit recovery program that allowed students to continue to earn course credits without the frustration of starting over at the beginning.

Although there is a resistance to encapsulate all Aboriginal learners as having distinct learning styles, Sawyer and Rodriguez (1993) suggested there are several dominant preferences for Aboriginals to learn: Visually presentating material, interacting with others, working in small groups, personally interpreting lessons, cooperating within environments, avoiding spotlighting, pacing of material, and accepting silence.The classes were mainly inquiry- or problem-based approaches and students worked in cooperative small groups.

\section{Physical}

The urban school attended to the primary students' needs for food, shelter, and transportation. An integrated services model was offered at the urban school to attend to non-academic needs that may arise and interfere with attending classes. The practical needs included various counselors, social workers, medical care, income assistance, community coordinators and parenting programs. Hot lunches and breakfast programs were offered to the students along with physical activities such as dance and sports. 
Women are the majority of Aboriginal learners (Spronk, 1995; Voyageur, 2001)indicating that gender issues such as childcare and other community responsibilities need to be met when preparing an appropriate learning environment for Aboriginal learners (Kirkup, 1996). The school offered daycare facilities within the school allowing the young mother to attend school with her baby.

The school created a positive learning space and the classrooms avoided the structure of typical desks in a row. Some classrooms had armchairs, couches, small round tables, and floor lamps. Sage would hang from the ceiling and there was a coffee pot on a table in the corner. Students were made to feel comfortable and teachers would move from table to table talking with students. Teachers were not found at the front of the classroom teaching and natural light or lamps were used to light the room instead of fluorescent lights. The teacher participants reported the school was welcoming and the door was always open.

\section{Emotional}

Both the school and teachers provided emotional support for their Aboriginal students. The teachers displayed love and a genuine caring nature. They understood with empathy the lives and challenges these students were triumphing over and encouraged and supported the students. The teacher-student relationship was described as family-like and this assisted the students in feeling more confident about their learning abilities. Students and teachers built trust between them and the students knew they were respected and cared for without fear of humiliation or shame. Teachers recognized that tests were highly stressful for their students and often would assess through conversations with their students. Students and teachers shared leadership in the learning environment by directing their learning. The school was on a first-name basis for both teachers and students demonstrating a non-hierarchical learning environment. A learning community was built by students often learning in small cooperative groups and capitalizing on the different skills the students had, allowing students to feel success.

\section{Conclusions}

This case study reported the teachers' perspectives of how they took arms against a sea of troubles and incorporated traditional Aboriginal pedagogy into the classrooms resulting in their Aboriginal students experiencing increased levels of credit completion, attendance, and graduation rates. As a result of incorporating an Aboriginal medicine wheel healing education model, the results over a four-year period were that credit completion improved from $31 \%$ to $81 \%$, attendance increased from $52 \%$ to $77 \%$ and graduation rates increased from 3 to 55 (personal communication, CG, November 17, 2016). The teachers, embraced traditional Aboriginal pedagogy, and this resulted in decolonized learning experiences for their Aboriginal students. The teaching style emulated traditional Aboriginal teaching by being hands-on, experiential, wholistic, personal, cooperative, flexible, and self-paced while incorporating Aboriginal culture and knowledge into the curriculum This case study represented education that brings the best of both education worlds into the classroom, and as a result, the students benefitted.

Infusing culture into the classrooms and the school had produced encouraging results including 
improved self-esteem and pride in being Aboriginal. The students reported their pride repeatedly in their graduation video recordings. Aboriginal peoples must still meet the requirements set by the mainstream education system; however, this case study endorses that Aboriginal pedagogical approaches can provide learning outcomes that meet government education standards. By the teacher becoming a healer and creating a healing environment that was loving and supportive, students and teachers built mutually respectful relationships that were non-hierarchical. Students were offered an integrated services model that also provided for the practical and non-academic needs of the students.

The Aboriginal pedagogical approach represented a wholisticmedicine wheel healing education model that attended to bringing balance and harmony to the students. The circle was completed wherein "only when our hearts, minds, bodies, and spirits work together do we truly have Indigenous education" (Archibald, 2008, p. 12). The classrooms of this study addressed the physical, emotional, intellect, and spiritual needs of its students. The learners were nurtured and experienced healing within the talking circles and in the teachers' relational approach to them as learners demonstrating mutual respect and equality. The Aboriginal learner enjoys success with this approach. To be, or not to be is no longer the question. The question is what needs to change for Aboriginal students to be successful in the classroom in the decolonization process? The process of change is slow, inevitable, and current efforts to combine and adapt mainstream education to incorporate Aboriginal culture is leading the way for better teaching and learning experiences. As Faye stated, "I think often times we get hung up on practices that work for Aboriginal students when in reality they [practices] work for every student."

\section{Acknowledgement}

This research was supported by the Social Sciences and Humanities Research Council (SSHRC) and awarded to Theresa A. Papp.

The author would like to thank the educational leaders that represented administration and teachers of the school selected for this case study and the appreciation for the teachers sharing their skills and knowledge with genuine passion for their students in the spirit of collaborating to further the knowledge and literature in helping Aboriginal students succeed academically.

\section{References}

Acoose, S., Blunderfield, D., Dell, C. A., \& Desjarlais, V. (2009). Beginning with our voices: How the experiential stories of First Nations women contribute to a national research project. Journal of Aboriginal Health, 4(2), 35-43.

Archibald, J. (2008). Indigenous storywork: Educating the heart, mind, body, and spirit. Vancouver, BC: UBC Press.

Battiste, J., \& Youngblood Henderson, J. (2000). Indigenous knowledge and heritage: A global challenge. Saskatoon, SK: Purich Publishing.

Battiste, M. (2002). Indigenous knowledge and pedagogy in First Nations education: A 
literature review with recommendations. Ottawa, ON: INAC.

Battiste, M. (2004, May). Animating sites of postcolonial education: Indigenous knowledge and humanities. Plenary Address presented at CSSE Winnipeg, MB.

Battiste, M. (2013). Decolonizing education: Nourishing the learning spirit. Saskatoon, SK: Purich.

Bell, D., Anderson, K., Fortin, T., Ottmann, J., Rose, S., Simard, L., \& Spencer, K. (2004). Sharing our success: Ten case studies in Aboriginal schooling. Kelowna, BC: Society for the Advancement of Excellence in Education.

Cajete, G. A. (1994). Look to the mountain: An ecology of Indigenous education. Skyland, NC: Kivaki Press.

Cajete, G.A. (1986). Science: An Native American perspective. (Doctoral dissertation) International College, Los Angeles, CA.

Castagno, A. E., \& Brayboy, B. M. J. (2008). Culturally responsive schooling for Indigeneous youth: A review of the literature. Review of Educational Research, 78(4), 941-993. https://doi.org/10.3102/0034654308323036

Castellano, M. B. (2016). Elders' teachings in the twenty-first century: A personal reflection. In D. Long and O. P. Dickason (Eds.), Fourth Edition. Visions of the heart: Issues involving Aboriginal Peoples in Canada, pp. 80-98. Don Mills, ON: Oxford University Press.

Castellano, M.B. (2000). Updating Aboriginal traditions of knowledge. In G.J. Sefi Dei, B.L. Hall \& D.G. Rosenberg (Eds.), Situating Indigenous knowledges: Definitions and boundaries (pp. 21-34). Toronto, ON: University of Toronto Press.

Charmaz, K. (2011). Grounded theory methods in social justice research. In N. K. Denzin \& Y. S. Lincoln (Eds.), The SAGE handbook of qualitative research (4th ed., pp. 359-380). Thousand Oaks, CA: SAGE.

Cherubini, L. (2014). Aboriginal student engagement and achievement: Educational practices and cultural sustainability. Vancouver, BC: UBC Press.

Cleary, L. M., \& Peacock, T. D. (1998). Collected wisdom: American Indian education. Boston, MA: Allyn and Bacon.

Couture, J. E. (2011). The role of Native Elders: Emergent issues. In D. Long and O. P. Dickason (Eds.), Third Edition. Visions of the heart: Canadian Aboriginal issues, pp. 18-34. Don Mills, ON: Oxford University Press.

Curwen Doige, L. A. (2003). A missing link: Between traditional Aboriginal education and the Western system of education. Canadian Journal of Native Education, 27(2), 144-160.

Ermine, W. (1995). Aboriginal epistemology. In M. Battiste and J. Barman (Eds.), First Nations education in Canada: The circle unfolds (pp. 101-112). Vancouver, BC: UBC Press.

Glaser, B. G. (2002). Grounded theory and gender relevance. Health Care for Women 
International 23, 786-793. https://doi.org/10.1080/07399330290112317

Glaser, B. G., \& Strauss, A. (1967). The discovery of grounded theory. Chicago, IL: Aldine Publishing.

Gordon, C. E., \& White, J. P. (2014). Indigenous educational attainment in Canada. The International Indigenous Policy Journal, 5(3), Article 6. https://doi.org/10.18584/iipj.2014.5.3.6

Graveline, F. J. (1998). Circle works: Transforming Eurocentric consciousness. Halifax, NS: Fernwood Publications.

Gruber, S.,\& Coldevin, G. (1994). Management training at a distance for Inuit administrators: The Atii pilot project. Journal of Distance Education, 9(2), 21-34.

Haig-Brown, C. (1995). Taking control: Contradiction and First Nationals adult education. In M. Battiste and J. Barman (Eds.), First Nations education in Canada (pp. 262-287). Vancouver, BC: UBC Press.

Hammond, Z. (2015). Culturally responsive teaching \& the brain: Promoting authentic engagement and rigor among culturally and linguistically diverse students. Thousand Oaks, CA: Corwin.

Hampton, E. (1995). Towards a redefinition of Indian education. In M. Battiste and J. Barman (Eds.), First Nations education in Canada: The circle unfolds (pp. 5-46). Vancouver, BC: UBC Press.

Hampton, E. (2000). First Nations - Controlled university education in Canada. In M. Brant Castellano, L. Davis, and L. Lahache (Eds.), Aboriginal education: Fulfilling the promise (pp. 208-223). Vancouver, BC: UBC Press.

Kanu, Y. (2002). In their own voices: First Nations students identify some cultural mediators of their learning in the formal school system. Alberta Journal of Educational Research, 48(2), 98-121.

Kanu, Y. (2006). Getting them through the college pipeline: Critical elements of instruction influencing school success among Native Canadian high school students. Journal of Advanced Academics, 18(1), 116-145. https://doi.org/10.4219/jaa-2006-348

Kanu, Y. (2011). Integrating Aboriginal perspectives into the school curriculum: Purposes, possibilities, and challenges. Toronto, ON: University of Toronto Press.

Katz, R., \& St. Denis, V. (1991). Teacher as healer, Journal of Indigenous Studies, 2(2), 23-35.

Kirkness, V. J. (1998). Our peoples' education: Cut the shackles; Cut the crap; Cut the mustard. Canadian Journal of Native Education 22(1), 10-15.

Kirkup, G. (1996). Chapter 10. The importance of gender. In. R. Mills \& A. Tait (Eds.) Supporting the learner in open and distance learning (pp. 146-164). London, UK: Pitman Publishing. 
Kovach, M. (2009). Indigenous methodologies: Characteristics, conversations, and contexts. Toronto, ON: University of Toronto Press.

Kovach, M. (2010). Conversational method in Indigenous research. First Peoples Child \& Family Review, 5(1), 40-48.

Lambert, L. (2004, May). Developing online science courses for native students: The Salish Kootenai Tribal College experience. Paper presented at the meeting of Manitoba Association for Distributed Leaning and Training (MADLaT), Winnipeg, MB.

Leddy, S., \& Turner, S. (2016). Two voices on Aboriginal pedagogy: Sharpening the focus. Journal of the Canadian Association for Curriculum Studies, 14(2), 53-65.

Little Bear, L. (2000). Jagged worldviews colliding. In M. Battiste (Ed.), Reclaiming Indigenous voice and vision (pp. 77-85). Vancouver, BC: UBC Press.

Little Bear, L. (2009). Naturalizing Indigenous knowledge: Synthesis paper. University of Saskatchewan, Aboriginal Education Research Centre, Saskatoon, SK and First Nations and Adult Higher Education Consortium, Calgary, AB. Retrieved from www.fnahec.org.

Ludema, J. D., Cooperrider, D. L., \& Barrett, F. J. (2001). Appreciative inquiry: The power of the unconditional positive question. In P. Reason \& H. Badbury (Eds.), Handbook of action research: Participative inquiry and practice (pp. 189-199). Thousand Oaks, CA: SAGE publications.

McMillan, J. H., \& Schumacher, S. (2010). Research in education: Evidence-based inquiry, (7th ed.). Upper Saddle River, NJ: Pearson.

Michell, C., Chief, M., Diubaldo, D., Kylne, D., McNab, W., \& Smith, L. (2013). In J. Silver (Ed.), Moving forward, giving back: Transformative Aboriginal adult education, (pp. 17-28). Black Point, NS: Fernwood.

Morin, M. (1998). Paradigm shifts. In S. Scott, B. Spencer \& A. Thomas, (Eds.) Learning for Life. Canadian readings in adult education (pp. 59-70). Toronto, ON: Thompson Educational Publishing, Inc.

Papp, T. A. (2016). Teacher strategies to improve education outcomes for Indigenous students. Comparative and International Education, 45(3), 1-14

Pewewardy, C. (1998). Our children can't wait: Recapturing the essence of Indigenous schools in the United States. Cultural Survival Quarterly, 22(1).

Pewewardy, C., \& Hammer, P. C. (2003). Culturally responsive teaching for American Indian students. Eric Digest.

Ponting, J.R. (1997). First Nations in Canada: Perspectives on opportunity, empowerment, and self-determination. Toronto, ON: McGraw-Hill Ryerson Limited.

Royal Commission on Aboriginal Peoples (1996). Volumes 1-5. Ottawa: Canadian Communications. 
Saldana, J. (2013). The coding manual for qualitative researchers. Thousand Oaks, CA: Thousand Oaks, CA: SAGE.

Sawyer, D., \& Rodriguez, C. (1993). How Native Canadians view literacy: A summary of findings. Journal of Reading, 36(4), 284-293.

Scott, C. L. (2015). The futures of learning 3: What kind of pedagogies for the $21^{\text {st }}$ century? United Nations Education Scientific and Cultural Organization Education Research and Foresight, Paris. [ERF Working Papers Series, No. 15].

Silver, J. (2013). Moving forward giving back: Transformative Aboriginal adult education. Winnipeg, MB: Fernwood.

Silver, J., Mallett, K., Greene, J., \& Simard, F. (2002). Aboriginal education in Winnipeg inner city high schools. Winnipeg inner-city research alliance: Canadian center for policy alternatives - Manitoba. Retrieved from http:/www.turtleisland.org/education/winnipeg.pdf

Simpson, L.R. (1998). Aboriginal peoples and the environment. Canadian Journal of Native Education, 22(2), 223-237.

Social Sciences and Humanities Research Council of Canada (SSHRC). (2016). Leveraging knowledge for $21^{\text {st }}$ century teaching and learning: Insights and opportunities for knowledge mobilization and future research. Ottawa, ON. Retrieved from http://www.sshrc-crsh.gc.ca/society-societe/community-communite/ifca-iac/01-learning_repo rt-apprentissage_rapport-eng.pdf

Spronk, B. (1995). Appropriating learning technologies: Aboriginal learner, needs, and practices. In J. Roberts \& E. Keough (Eds.) Why the information highway? Lessons from open and distance learning (pp. 77-101). Toronto, ON: Trifolium Books.

Voyageur, C. (2001). Ready, willing and able: Prospects for distance learning in Canada's First Nations community. Journal of Distance Education, 16(1), 102-112.

Wilson, S. (2001). What is Indigenous research methodology? Canadian Journal of Native Education, 25(2), 175-179.

Wilson, S. (2008). Research is ceremony: Indigenous research methods. Black Point, NS: Fernwood Publishing.

\section{Footnotes}

1 According to Statistics Canada (2007), there is no one correct definition for Aboriginal peoples and the choice can depend on the focus and purpose. Aboriginal peoples, according to Indigenous and Northern Affairs Canada (INAC), are the "the descendants of the original inhabitants of North America. The Canadian Constitution recognizes three groups of Aboriginal people - Indians [First Nation], Metis and Inuit. These are three separate peoples with unique heritages, languages, cultural practices and spiritual beliefs" (2018). INAC explained that the word "Indian" had been found offensive by some people and had been replaced in the 1970s with the term "First Nations peoples" which although not a legal 
definition, refers to both Status and non-Status Indian peoples in Canada (2018).

2. A definition of education "is the process by which knowledge, values, language, culture, and skills are transmitted from one generation to the next: empowerment that enables individuals to pursue choices and opportunities" (Steeves, Carr-Stewart, \& Marshall, 2010, p. 19).

3 The terminology of student success and effective teaching strategies is a more abstract term. The term success and equitable outcomes can take many forms. The Canadian Council on Learning (CCL) offers three models for Holistic Lifelong Learning that is grounded on key attributes of Aboriginal Learning that include Aboriginal languages, cultures, spirituality, communal activity, experiential integrating Western knowledge (2007). Western standards use graduation, attendance, and course credits to measure success and to graduate from high school called the Assessments for Learning (AFL) scores. This research will use the AFL scores as the initial measure of success.

4 The term Indigenous is used on the worldwide stage to identify people that are descendants ". . . of those who inhabited a country or a geographical region at the time when people of different cultures or ethnic origins arrived. The new arrivals later became dominant through conquest, occupation, settlement or other means" (United Nations, 2014). 